\title{
Vulnerabilidade socioambiental na metrópole paulistana: uma análise sociodemográfica das situações de sobreposição espacial de problemas e riscos sociais e ambientais ${ }^{*}$
}

\author{
Humberto Prates da Fonseca Alves*
}

\begin{abstract}
Este trabalho procura identificar e caracterizar populações em situação de vulnerabilidade socioambiental em São Paulo, através da construção de indicadores ambientais, em escala desagregada (setores censitários do IBGE). A vulnerabilidade socioambiental está sendo definida como a coexistência ou sobreposição espacial entre grupos populacionais muito pobres e com alta privação (vulnerabilidade social) e áreas de risco ou degradação ambiental (vulnerabilidade ambiental). A metodologia baseia-se na construção de um Sistema de Informação Geográfica (SIG), em que se sobrepõe a cartografia da rede hidrográfica à malha dos setores censitários do município de São Paulo (censo 2000). Inicialmente, identificam-se os setores classificados como de alta vulnerabilidade social pelo Mapa da vulnerabilidade social da população da cidade de São Paulo (CEM-CEBRAP/SAS-PMSP, 2004). Posteriormente, os setores localizados às margens de cursos $d$ 'água e com baixa cobertura de esgoto são considerados proxy de áreas com alta vulnerabilidade ambiental. Os resultados mostram que, no interior do grupo de setores censitários de alta vulnerabilidade social, existem grandes diferenças nas condições socioeconômicas e demográficas, relacionadas às diversas categorias de vulnerabilidade ambiental.
\end{abstract}

Palavras-chave: Vulnerabilidade socioambiental. Risco ambiental. Indicadores socioambientais. Vulnerabilidade social. Metrópole de São Paulo. Populações em situação de risco. Geoprocessamento.

\section{Introdução}

Este trabalho procura operacionalizar empiricamente a categoria vulnerabilidade socioambiental, com o objetivo de identificar e caracterizar populações nesta situação, no município de São Paulo, por meio da construção de indicadores ambientais na unidade espacial de análise mais desagregada possível (setores censitários do censo demográfico do IBGE). Para fins metodológicos e analíticos, a vulnerabilidade socioambiental está sendo definida como a coexistência ou sobreposição espacial entre grupos populacionais muito pobres e com alta privação (vulnerabilidade social) e áreas de risco ou degradação ambiental (vulnerabilidade ambiental). Neste sentido, é justamente a combinação destas duas dimensões que está sendo considerada

\footnotetext{
* Uma primeira versão deste artigo foi apresentada no XI Encontro da Associação Nacional de Pós-graduação e Pesquisa em Planejamento Urbano e Regional (Anpur), realizado em Salvador (BA), de 23 a 27 de maio de 2005. Esta versão foi revisada e ampliada.

${ }^{* \star}$ Economista, doutor em Ciências Sociais (Unicamp) e pós-doutorando e pesquisador do Centro de Estudos da Metrópole (CEMCebrap).
} 
uma situação de vulnerabilidade socioambiental.

Entendemos que não é por acaso que as áreas de risco e degradação ambiental também são, na maioria das vezes, áreas de pobreza e privação social. Assim, nossa hipótese é de que a vulnerabilidade ambiental é um fator relevante na configuração da distribuição espacial das situações de pobreza e privação social na metrópole paulistana. Nesse sentido, a categoria vulnerabilidade socioambiental pode captar e traduzir os fenômenos de sobreposição espacial e interação entre os problemas sociais e ambientais, sendo adequada para uma análise da dimensão socioambiental (e espacial) da pobreza.

A metodologia geral do trabalho consiste na construção de um sistema de informação geográfica, através do qual é feita a sobreposição da cartografia digital da rede hidrográfica à malha digital dos setores censitários do município de São Paulo (censo 2000). Inicialmente, são identificados os setores classificados como de alta vulnerabilidade social, pelo Mapa da vulnerabilidade social da população da cidade de São Paulo (CEM-CEBRAP/SASPMSP, 2004). Posteriormente, aplica-se uma tipologia para medir o grau de vulnerabilidade ambiental destas áreas, sendo que os setores censitários localizados às margens de cursos d'água e com baixa cobertura de esgoto são classificados como proxy de áreas com alta vulnerabilidade ambiental.

Os resultados da análise mostram que as áreas com alta vulnerabilidade ambiental apresentam condições socioeconômicas significativamente piores, além de maior concentração de crianças e jovens, do que aquelas com menor grau de vulnerabilidade ambiental, o que revela a existência de áreas críticas, onde ocorre forte concentração de problemas e riscos sociais e ambientais.

Nesse sentido, a identificação e a caracterização de alguns padrões específicos de sobreposição espacial de situações de pobreza e risco/degradação ambiental, existentes na metrópole paulistana, requerem o desenvolvimento de análises muito detalhadas, tais como aquelas possibilitadas pelos sistemas de informações geográficas, utilizando unidades espaciais de análise extremamente desagregadas, como os setores censitários. Portanto, uma possível contribuição deste trabalho é dar visibilidade às áreas identificadas como de alta vulnerabilidade socioambiental, podendo trazer subsídios relevantes para o planejamento de políticas públicas sociais e ambientais, tais como habitação e saneamento.

\section{Breve revisão da literatura}

Na Região Metropolitana de São Paulo, a despeito da melhora dos indicadores sociais médios das periferias, nas duas últimas décadas, constata-se a existência de grandes diferenciais de condições de vida e de acesso a serviços públicos, com a presença de áreas extremamente pobres e carentes de equipamentos e serviços, espaIhadas por toda a periferia metropolitana. Assim, sob padrões médios de atendimento muito melhorados, existiriam situações de extrema pauperização e péssimas condições sociais e exposição cumulativa a diversos tipos de risco (TORRES e MARQUES, 2001).

Segundo dados da PNAD-IBGE de 1998, existe um grande contingente populacional, de cerca de 1,7 milhão de pessoas (10\% da população da RMSP), com renda familiar inferior a dois salários mínimos, que não têm acesso à moradia nas áreas periféricas mais tradicionais e mesmo em favelas consolidadas, sendo obrigadas a residirem nas franjas e interstícios urbanos mais precários, geralmente em áreas de risco ambiental, com péssimos indicadores sociais e sanitários (TORRES e MARQUES, 2001).

O nível dos problemas sociais e ambientais de determinadas áreas é impressionante, superpondo, em termos espaciais (e sociais), os piores indicadores socioeconômicos com riscos de enchentes e deslizamentos de terra, um ambiente intensamente poluído e serviços sociais (quando os há) extremamente ineficientes (TORRES et al., 2003, p. 5). 
Assim, em alguns espaços da periferia, verifica-se intensa concentração de indicadores negativos, que sugerem a presença de "pontos críticos" de vulnerabilidade social (e ambiental), revelando a existência de uma espécie de periferia da periferia (TORRES e MARQUES, 2001).

$\mathrm{Na}$ Zona Leste de São Paulo, as áreas de risco ambiental (definidas como os setores censitários localizados a até 100 metros dos cursos d'água) apresentam maiores concentrações de população pobre e de domicílios em precárias condições sanitárias (principalmente o acesso à rede de esgoto), bem como proporções mais elevadas de crianças e adolescentes e de favelas. De fato, as condições precárias de urbanização e saneamento, vigentes na periferia, fazem com que a residência em locais próximos de cursos d'água implique exposição real a diversos riscos ambientais, pois, além das enchentes (sazonais e com menor abrangência geográfica), há um contato direto com a água contaminada e exposição a vetores de doenças de veiculação hídrica. Assim, no caso da Zona Leste, constatou-se a existência de significativa correlação positiva entre exposição a risco ambiental e pobreza (TORRES, 1997).

Para Jacobi (1995), há uma relação direta entre exposição a riscos ambientais e precariedade de acesso a serviços públicos. A própria ausência de infraestrutura urbana (água, esgoto, coleta de lixo, canalização de córregos, etc.) expõe as populações residentes nestas áreas a riscos ambientais, como as doenças de veiculação hídrica.

Portanto, há uma tendência de os grupos de baixa renda residirem em áreas com más condições urbanísticas e sanitárias e em situações de risco e degradação ambiental (como, por exemplo, terrenos próximos de cursos d'água e de lixões ou com alta declividade). A explicação mais geral é que estas constituem as únicas áreas acessíveis à população mais pobre, seja porque são áreas públicas e/ou de preservação (invadidas), seja porque tratase de áreas muito desvalorizadas no mercado de terras, por serem pouco propícias à ocupação, devido às características de risco e à falta de infra-estrutura urbana (TORRES, 1997).

Nas duas últimas décadas, também tem ocorrido um forte processo de expansão e periferização das favelas da RMSP, particularmente no município de São Paulo. As favelas em geral ocupam áreas públicas que, muitas vezes, localizam-se em fundos de vale e beiras de córregos, com risco de enchentes, ou em encostas com declividades acentuadas, com alta propensão à erosão. Como a maioria dos domicílios localizados em favelas não possui rede de esgoto, em geral os dejetos têm como destino o córrego mais próximo ou fossas rudimentares, que contaminam o lençol freático, gerando alto risco sanitário e poluição dos mananciais hídricos (TORRES e MARQUES, 2002; TASCHNER, 2000).

\section{A categoria vulnerabilidade}

A noção de vulnerabilidade geralmente é definida como uma situação em que estão presentes três elementos (ou componentes): exposição ao risco; incapacidade de reação; e dificuldade de adaptação diante da materialização do risco (MOSER, 1998).

Nos últimos anos, o termo vulnerabilidade social tem sido utilizado com certa freqüência por grupos acadêmicos e entidades governamentais da América Latina. Esta incorporação da noção de vulnerabilidade teve forte influência de organismos internacionais, como as Nações Unidas, o Banco Mundial e o Bird. Parte da visibilidade dos estudos sobre vulnerabilidade social deve-se a uma certa insatisfação com os enfoques tradicionais sobre pobreza e com seus métodos de mensuração, baseados exclusivamente no nível de renda monetária e em medidas fixas, como a linha de pobreza. Neste sentido, a noção de vulnerabilidade social, ao considerar a insegurança e a exposição a riscos e perturbações provocadas por eventos ou mudanças econômicas, daria uma visão mais ampla sobre as condições de vida dos grupos sociais mais pobres e, ao mesmo tempo, consideraria a disponibilidade de recursos e estratégias das próprias famílias 
para enfrentarem os impactos que as afetam (CEPAL, 2002; KAZTMAN et al., 1999).

Uma outra linha de análise sobre vulnerabilidade, desenvolvida principalmente dentro da geografia, tem origem nos estudos sobre desastres naturais (natural hazards) e avaliação de risco (risk assessment). Nesta perspectiva, a vulnerabilidade pode ser vista como a interação entre o risco existente em um determinado lugar (hazard of place) e as características e o grau de exposição da população lá residente (CUTTER, 1994). Nas palavras de Cutter (1996, p. 533), "vulnerability is conceived as both a biophysical risk as well as a social response, but within a specific area or geographic domain".

A noção de vulnerabilidade também tem se tornado, nos últimos anos, um foco central para as comunidades científicas de mudança ambiental e sustentabilidade (IHDP, IGBP, IPCC ${ }^{1}$ ) e uma categoria analítica importante para instituições internacionais, como algumas agências das Nações Unidas (Pnud, Pnuma, $\mathrm{FAO}^{2}$ ) e o Banco Mundial (KASPERSON e KASPERSON, 2001). Uma questão bastante mencionada, por exemplo, é a vulnerabilidade em relação aos recursos hídricos: escassez de água potável; falta de saneamento; e contato com doenças de veiculação hídrica. A população pobre geralmente não tem acesso a saneamento adequado (água e esgoto) e, muitas vezes, é forçada a residir em áreas expostas a altos níveis de poluição hídrica. Estima-se que $20 \%$ da população mundial não tem acesso a água potável e $50 \%$ não dispõe de saneamento adequado. Doenças de veiculação hídrica representam séria ameaça à saúde humana, principalmente para as crianças, que são as mais vulneráveis a estas doenças (IHDP, 2001).

Com relação à literatura brasileira sobre o tema, alguns autores desenvolvem uma discussão sistemática sobre o conceito de vulnerabilidade, procurando analisar a utilização deste conceito em diferentes disciplinas, principalmente na geografia e na demografia (MARANDOLA e HOGAN, 2005; HOGAN e MARANDOLA, 2005).

$O$ interesse dos geógrafos e dos demógrafos tem confluído, principalmente, com preocupações mais recentes destes últimos sobre as populações em situações de risco. Ambos passam a ocupar-se de estudos sobre enchentes e deslizamentos, entre outras situações em que o ambiente, conjugado a fatores socioeconômicos, expõe as populações a riscos, sobretudo nas cidades (MARANDOLA e HOGAN, 2005, p. 30).

Segundo esses autores, a demografia, à semelhança da geografia, tem trazido a vulnerabilidade como conceito complementar ao de risco. Neste sentido, o Grupo de Trabalho sobre População e Meio Ambiente, da Associação Brasileira de Estudos Populacionais (ABEP), tem tido papel fundamental no avanço conceitual e metodológico, no contexto da demografia, nos estudos sobre risco e vulnerabilidade. Um dos conceitos centrais abordados pelos pesquisadores deste grupo foi 0 de populações em situação de risco.

Torres (2000) discute teoricamente o conceito de risco ambiental, debatendo sobre os problemas e as dificuldades para sua operacionalização. Para o autor, um dos aspectos mais relevantes diz respeito à questão da cumulatividade de riscos de diferentes origens. Nesse sentido, as áreas de risco ambiental (próximas de lixões, sujeitas a inundações e desmoronamentos), muitas vezes, são as únicas acessíveis às populações de mais baixa renda, que acabam construindo nesses locais domicílios em condições precárias, além de enfrentarem outros problemas sanitários e nutricionais.

Finalmente, também não se pode deixar de destacar as diferenças de abordagem entre os estudos sobre vulnerabilidade social e aqueles a respeito da vulnerabi-

\footnotetext{
${ }^{1}$ IHDP (International Human Dimensions Programme on Global Environmental Change); IGBP (International Geosphere-Biosphere Programme); IPCC (Intergovernmental Panel on Climate Change).

${ }^{2}$ Pnud (Programa das Nações Unidas para o Desenvolvimento); Pnuma (Programa das Nações Unidas para o Meio Ambiente); FAO (Food and Agriculture Organization).
} 
lidade ambiental. Na literatura mais sociológica sobre o tema (MOSER, 1998; KAZTMAN et al., 1999), a vulnerabilidade social é analisada em relação a indivíduos, famílias ou grupos sociais. Já na geografia e nos estudos sobre riscos e desastres naturais (CUTTER, 1994; 1996), a vulnerabilidade ambiental tem sido discutida em termos territoriais (regiões, ecossistemas). Portanto, esta disparidade entre as duas tradições de estudos sobre vulnerabilidade, em termos de escala e de tipo de objeto de análise, deve ser considerada na construção da noção de vulnerabilidade socioambiental, a qual pretende integrar as duas dimensões - a social e a ambiental.

Assim, como decorrência destas diferenças de escala e unidade de análise, utilizadas para medir a vulnerabilidade, colocam-se limitações importantes para a operacionalização empírica da categoria vulnerabilidade socioambiental. No presente trabalho, por exemplo, esta limitação deve-se ao fato de que a informação utilizada para medir a vulnerabilidade socioambiental, cuja fonte são os resultados do universo do censo demográfico, está agregada por área (setor censitário). Esta agregação impede que a análise da vulnerabilidade seja feita na escala das famílias e domicílios, na tradição da sociologia. Ou seja, na realidade, está sendo considerada a vulnerabilidade de áreas, onde se localizam estas famílias e domicílios. Porém, cabe enfatizar que não estamos medindo a vulnerabilidade do território, mas sim a da população residente naquele território.

Tendo em vista esta breve revisão da literatura, consideramos que a vulnerabilidade socioambiental é uma categoria analítica que pode expressar os fenômenos de interação e cumulatividade entre situações de risco e degradação ambiental (vulnerabilidade ambiental) e situações de pobreza e privação social (vulnerabilidade social), apesar das limitações empíricas para operacionalização destas categorias analíticas, conforme destacado acima.

\section{Metodologia}

Como já mencionado, o objetivo deste trabalho é operacionalizar a categoria vulnerabilidade socioambiental. Para tanto, foram construídos indicadores que representassem as dimensões dessa vulnerabilidade: risco ambiental; degradação ambiental; e pobreza/vulnerabilidade social. Por razões metodológicas, ligadas à divulgação dos dados censitários agregados por área (setor censitário), as unidades de análise da vulnerabilidade socioambiental são áreas, no caso os 13 mil setores censitários do município de São Paulo.

Como foi dito, a metodologia geral do trabalho é a construção de um sistema de informação geográfica, através do qual se faz a sobreposição da cartografia digital da rede hidrográfica ${ }^{3}$ à malha digital dos setores censitários do município de São Paulo (Censo Demográfico 2000). ${ }^{4}$

Assim, para construir metodologicamente o objeto de análise - as situações de vulnerabilidade socioambiental -, são realizados alguns procedimentos, descritos a seguir. Em primeiro lugar, operacionalizase a categoria vulnerabilidade social, através da utilização dos dados do Mapa da vulnerabilidade social da população da cidade de São Paulo (CEM-CEBRAP/SASPMSP, 2004). ${ }^{5}$

Esse Mapa classificou os mais de 13 mil setores censitários do município de São

\footnotetext{
${ }^{3}$ A cartografia da rede hidrográfica do município de São Paulo foi desenvolvida pelo CEM-Cebrap e possui uma escala bastante detalhada (1:10.000), abrangendo todos os rios e represas de médio e grande portes e a maioria dos córregos do município. Através desta cartografia, podemos identificar as áreas localizadas muito próximas e/ou às margens dos cursos d'água (rios, represas e córregos), que estamos considerando como áreas de risco ambiental, ou seja, que apresentam risco de enchentes e/ou de contato com doenças de veiculação hídrica.

${ }^{4}$ À malha dos setores censitários estão associadas todas as variáveis do Censo Demográfico de 2000, relativas ao questionário do universo.

${ }^{5} \mathrm{Na}$ operacionalização da categoria vulnerabilidade social, estamos cientes das limitações empíricas impostas pela agregação por áreas dos dados do Censo 2000, utilizados para medir a vulnerabilidade social. Ou seja, no Mapa da vulnerabilidade social, as unidades espaciais de análise foram áreas (setores censitários) e não famílias e domicílios.
} 
Paulo em oito grupos de vulnerabilidade social, com base na combinação de um indicador de privação social com indicadores demográficos, especialmente estrutura etária. ${ }^{6}$

No presente trabalho, decidiu-se agregar os oito grupos de vulnerabilidade social em três grandes grupos, denominados de alta, média e baixa vulnerabilidade social, reunindo aqueles com patamar semelhante de vulnerabilidade social. Se esta agregação, por um lado, reduz a diversidade e a riqueza de situações de vulnerabilidade social, por outro, facilita muito a comparação entre os grupos, além de simplificar o cruzamento posterior com as categorias de vulnerabilidade ambiental.

Para operacionalizar a categoria vulnerabilidade ambiental, foram construídos e analisados indicadores ambientais, relativos à proximidade de cursos d'água e à cobertura de esgoto. Assim, estão sendo levadas em conta duas dimensões da vulnerabilidade ambiental: a exposição ao risco ambiental, que corresponde à residência em áreas muito próximas de cursos d'água (a menos de 50 metros), representando risco de enchentes e doenças de veiculação hídrica; ${ }^{7}$ e a exposição à degradação ambiental (ou má qualidade ambiental), que se refere à residência em áreas com baixa cobertura da rede de esgoto. ${ }^{8}$ Portanto, considera-se que a combinação destas duas dimensões compõe uma situação de vulnerabilidade ambiental.

Para efeitos metodológicos e analíticos, propõe-se uma tipologia bastante simples, em que os setores censitários do município de São Paulo são classificados em quatro categorias de vulnerabilidade ambiental, resultantes da combinação das duas dimensões - risco ambiental (proximidade dos cursos d'água) e degradação ambiental (baixa cobertura de esgoto).

Assim, foram definidas duas faixas de risco ambiental: alto, para as áreas (setores censitários) localizadas a menos de 50 metros dos cursos d'água; e baixo, para aquelas situadas fora deste limite. ${ }^{9} \mathrm{Da}$ mesma forma, foram definidas duas faixas de degradação ambiental: alta, para as áreas (setores) com cobertura de esgoto abaixo de $50 \%$ dos domicílios; e baixa, para aquelas com cobertura superior a $50 \%$ dos domicílios.

A partir da combinação das variáveis proximidade de cursos $d$ 'água e cobertura de esgoto, foram construídas quatro categorias (ou faixas) de vulnerabilidade ambiental, ao nível do setor censitário:

- baixa vulnerabilidade ambiental (categoria 1 - baixo risco e baixa degradação ambiental) - mais de $50 \%$ da área do setor censitário fora da margem de 50 metros de curso d'água e cobertura de rede de esgoto superior a $50 \%$ dos domicílios;

- média vulnerabilidade ambiental (categoria 2 - alto risco e baixa degradação ambiental) - mais de $50 \%$ da área do setor censitário dentro da margem de 50 metros de curso d'água e cobertura de rede de esgoto superior a $50 \%$ dos domicílios;

\footnotetext{
${ }^{6}$ De maneira muito resumida, descreve-se a seguir a metodologia de construção do Mapa da vulnerabilidade social. Inicialmente, foram selecionadas variáveis relevantes para a caracterização das múltiplas dimensões da vulnerabilidade social, tais como renda, escolaridade, condições de habitação e estrutura etária. Todas as variáveis foram selecionadas a partir dos resultados do universo do Censo Demográfico 2000. O conjunto inicial de variáveis selecionadas foi reduzido, através de análise fatorial (componentes principais), visando a construção de indicadores sintéticos que captassem a heterogeneidade de situações (de vulnerabilidade social) existentes no município de São Paulo. A análise fatorial produziu duas dimensões explicativas de vulnerabilidade - a socioeconômica e a demográfica. Para a construção do Mapa da vulnerabilidade social, os cerca de 13 mil setores censitários do município de São Paulo foram classificados em oito grupos, através de uma análise de agrupamentos (cluster), a partir de combinações entre as dimensões demográfica e socioeconômica (CEM-CEBRAP/SAS-PMSP, 2004).

${ }^{7}$ Apesar de ser uma abordagem parcial, na qual está sendo considerado apenas um tipo de risco ambiental, acredita-se que a proximidade em relação a cursos d'água, principalmente quando analisada em conjunto com a cobertura de esgoto, pode trazer elementos importantes para a análise da vulnerabilidade ambiental na metrópole paulistana.

${ }^{8}$ Nestas áreas, as precárias condições sanitárias fazem com que o esgoto seja lançado diretamente nos cursos d'água ou em fossas, que poderão contaminar o lençol freático e posteriormente os cursos d'água.

${ }^{9}$ Mais especificamente, consideram-se de alto risco os setores censitários com mais de $50 \%$ de sua área dentro das margens de 50 metros de cursos d'água, e de baixo risco aqueles com menos de $50 \%$ de sua área dentro destas margens de cursos d'água.
} 
- média vulnerabilidade ambiental (categoria 3 - baixo risco e alta degradação ambiental) - mais de $50 \%$ da área do setor censitário fora da margem de 50 metros de curso d'água e cobertura de rede de esgoto inferior a $50 \%$ dos domicílios;

- alta vulnerabilidade ambiental (categoria 4 - alto risco e alta degradação ambiental) - mais de 50\% da área do setor censitário dentro da margem de 50 metros de curso d'água e cobertura de rede de esgoto inferior a $50 \%$ dos domicílios.

O método utilizado para classificar a exposição ao risco ambiental (ou seja, a proximidade e contigüidade dos setores censitários aos cursos d'água) foi o cálculo da porcentagem da área do setor sobreposta às margens de 50 metros dos cursos d'água. ${ }^{10}$ Para tanto, foram gerados buffers (faixas) de 50 metros nas duas margens de todos os cursos d'água e sobrepostos aos setores censitários do município de São Paulo. Com isso, pôde-se calcular o tamanho e a porcentagem da área de cada setor que estava (ou não) sobreposta às margens dos cursos d'água. ${ }^{11}$

A escolha da proximidade inferior a 50 metros dos cursos d'água como parâmetro para definição de alto risco ambiental foi feita com base em dois critérios principais. Primeiro, procurou-se identificar as populações residentes em áreas realmente próximas de cursos d'água e que estão, de fato, expostas aos riscos de enchentes e de contato direto com doenças de veiculação hídrica. De acordo com a literatura sobre o tema, esta situação é típica de grande parte das favelas de São Paulo, que ocupam as várzeas dos rios e córregos (fundos de vale), por serem áreas com restrições à ocupação por motivos geotécnicos ou ambientais (TASCHNER, 2000).

Em segundo lugar, tomou-se como referência a regulamentação das Áreas de Preservação Permanente (APPs) do Código Florestal (leis 4771/65, 7803/89 e 7875/89), que estabelece faixas de proteção ambiental ao longo dos rios e de qualquer curso d'água. Conforme estas leis, não são permitidas a supressão de vegetação e a ocupação humana ao longo de qualquer curso d'água, em faixa marginal cuja largura mínima seja de trinta metros para os cursos d'água de menos de dez metros de largura e de cinqüenta metros para os cursos d'água que tenham de dez a cinqüenta metros de largura. Assim, como a maioria dos cursos d'água existentes no município de São Paulo possui largura inferior a 50 metros, considerou-se que a proximidade de 50 metros é adequada para expressar as áreas com restrições am-bientais à ocupação.

Por último, cabe ressaltar que estamos adotando critérios bastantes rígidos, na construção do indicador de vulnerabilidade ambiental (risco e degradação ambiental), ao considerarmos como critério de alto risco a localização do setor censitário às margens de 50 metros dos cursos d'água e mais da metade da área do setor sobreposta a estas margens, além da cobertura de esgoto inferior a $50 \%$ dos domicílios do setor, como critério de alta degradação. Se tivéssemos adotado outros critérios (ou outras metodologias), provavelmente teríamos encontrado um maior volume populacional com alta vulnerabilidade ambiental. Porém, como foi dito, nosso objetivo neste trabalho é identificar as áreas realmente críticas, com forte concentração de problemas e riscos sociais e ambientais, e que devem ser alvo prioritário de políticas públicas sociais e ambientais.

\footnotetext{
${ }^{10}$ Poderiam ser utilizados outros métodos para estimar a população residente em áreas próximas de cursos d'água, tais como o método overlayer, que permite atribuir às áreas localizadas às margens de cursos d'água os dados dos setores censitários sobrepostos a elas, na proporção em que as áreas dos setores participam das áreas à beira dos cursos d'água. Porém, neste trabalho, optouse por utilizar o setor censitário como unidade espacial de análise, o que permite localizar com mais facilidade e precisão as áreas críticas, com alta vulnerabilidade socioambiental, espalhadas pela malha urbana da metrópole paulistana.

${ }_{11}$ Para calcular as áreas dos setores censitários sobrepostas às margens dos cursos d'água, utilizou-se o software ESRI ArcView 3.2.
} 


\section{Os três grandes grupos de vulnerabili- dade social do município de São Paulo: análise comparativa dos indicadores socioeconômicos e demográficos}

No Mapa da vulnerabilidade social, os grupos 1 e 2 (que aqui foram agregados no grupo de baixa vulnerabilidade social) possuem as melhores condições de vida do município de São Paulo, englobando famílias não-vulneráveis, ou seja, nãoexpostas à dimensão da privação socioeconômica e com baixa presença de crianças e adolescentes. Os grupos 3, 4 e 6 (reunidos no grupo de média vulnerabilidade social) apresentam situações de baixa a média privação social (CEM-CEBRAP/SAS-PMSP, 2004). ${ }^{12}$

Os grupos 5, 7 e 8 do Mapa da vulnerabilidade social foram agregados no grupo de alta vulnerabilidade social. Os grupos 5 e 8 possuem os piores indicadores socioeconômicos do município, além de concentrarem os chefes de domicílio mais jovens e a maior presença de crianças. $O$ grupo 7 apresenta indicadores socioeconômicos um pouco melhores do que os outros dois, mas possui quase um terço de chefes de domicílio mulheres com baixa escolaridade, além de grande presença de adolescentes (CEM-CEBRAP/SAS-PMSP, 2004).

A agregação dos oito grupos do Mapa da vulnerabilidade social, em três grandes grupos de vulnerabilidade social (Tabela 1), resultou nos volumes populacionais apresentados a seguir. Nas áreas (setores censitários) com alta vulnerabilidade social, residem mais de 3 milhões de pessoas, o que corresponde a $29,2 \%$ da população do município de São Paulo, em 2000. Já naquelas com média vulnerabilidade social moram 5,1 milhões de pessoas $(48,4 \%$ da população municipal), enquanto nas áreas com baixa vulnerabilidade social vivem 2,3 milhões de pessoas, que representam $22,1 \%$ dos habitantes do município, em $2000^{13}$ (ver Mapa 1 e Tabelas 1 e 2).

A comparação dos indicadores socioeconômicos e demográficos dos três grandes grupos de vulnerabilidade social mostrou as expressivas diferenças entre eles (Tabela 2).

Inicialmente, analisou-se o acesso a serviços públicos, no caso as condições de saneamento básico, para os três grandes

TABELA 1

Correspondência entre os oito grupos do Mapa da vulnerabilidade social e os três grandes grupos de vulnerabilidade social

\begin{tabular}{lc}
\hline Grupos do Mapa da vulnerabilidade social & Grupos de vulnerabilidade social \\
\hline $\begin{array}{l}\text { Grupo } 1 \text { (nenhuma privação) } \\
\text { Grupo } 2 \text { (privação muito baixa) }\end{array}$ & Baixa vulnerabilidade social \\
\hline $\begin{array}{l}\text { Grupo } 3 \text { (baixa privação e famílias idosas) } \\
\text { Grupo } 6 \text { (média baixa privação e famílias idosas) } \\
\text { Grupo } 4 \text { (média privação e famílias adultas) }\end{array}$ & Média vulnerabilidade social \\
\hline $\begin{array}{l}\text { Grupo } 5 \text { (alta privação e famílias jovens) } \\
\text { Grupo } 7 \text { (alta privação e famílias adultas) } \\
\text { Grupo } 8 \text { (altíssima privação e famílias jovens) }\end{array}$ & Alta vulnerabilidade social \\
\hline
\end{tabular}

Fonte: CEM-Cebrap, SAS-PMSP (2004).

\footnotetext{
${ }^{12}$ No grupo 3, destacam-se presença de famílias idosas, baixa participação de crianças e adolescentes e indicadores razoáveis de renda e escolaridade. No grupo 6, com média-baixa privação social e famílias adultas, destaca-se a significativa presença de mulheres responsáveis pelo domicílio pouco escolarizadas. Já o grupo 4 apresenta níveis médios de privação e alta concentração de jovens chefes de domicílio com baixa escolaridade (CEM-CEBRAP /SAS-PMSP, 2004).

${ }^{13}$ É importante reafirmar que os grupos de vulnerabilidade social referem-se a áreas e não a indivíduos ou domicílios. Assim, um determinado grupo de vulnerabilidade social corresponde a um conjunto de áreas (setores censitários) com características sociodemográficas consideradas de alta, média ou baixa vulnerabilidade social. Ou seja, são áreas cujas características sociodemográficas da população predominantemente ali residente são de alta, média ou baixa vulnerabilidade social.
} 
MAPA 1

Setores censitários classificados segundo três grandes grupos de vulnerabilidade social Município de São Paulo - 2000

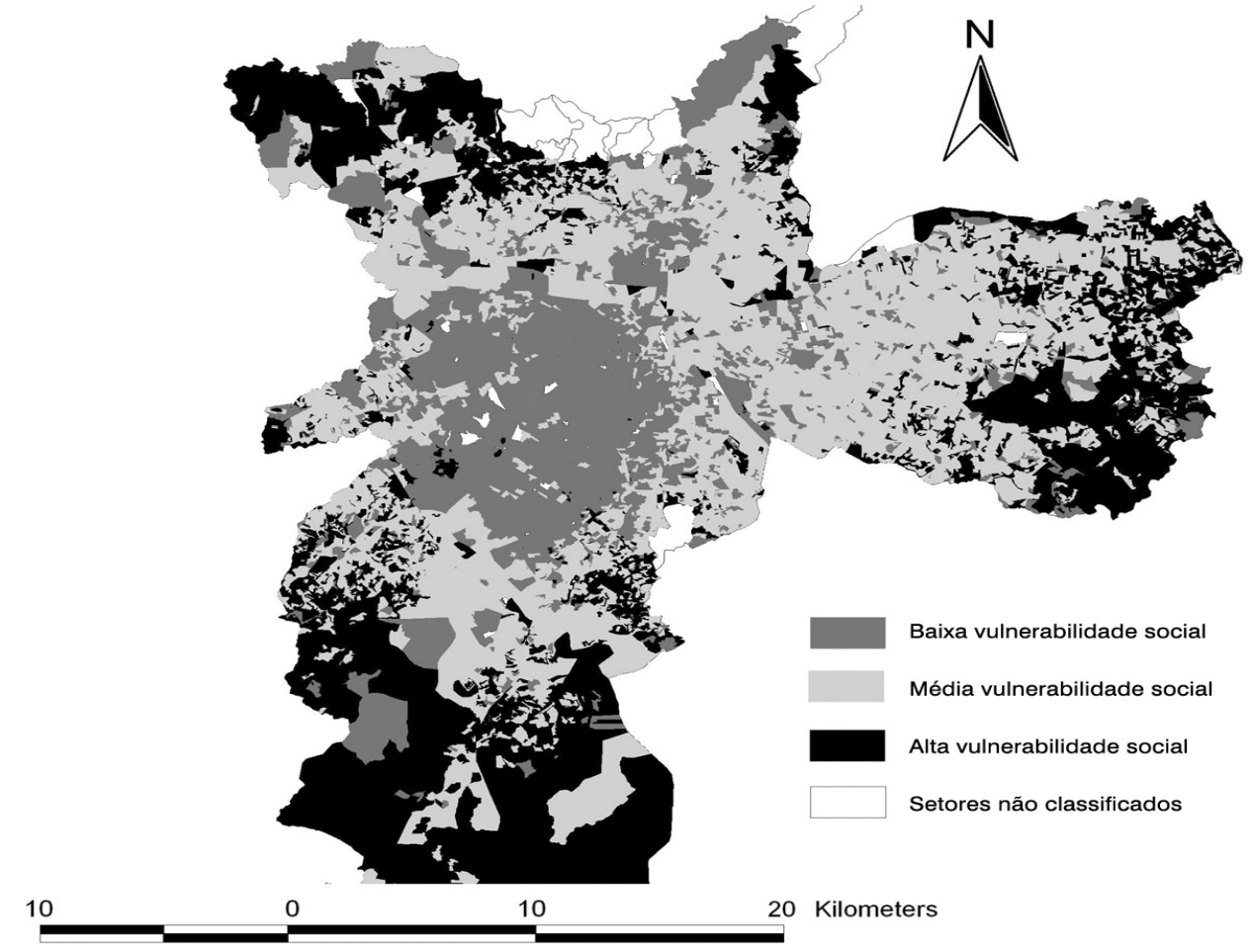

Fonte: CEM-Cebrap, SAS-PMSP (2004); IBGE, Malha digital dos setores censitários do município de São Paulo (censo 2000).

grupos (agregados de setores) de vulnerabilidade social. Como mostram os indicadores da Tabela 2, as diferenças entre os três grupos são muito pequenas em relação às coberturas da rede de abastecimento de água e da coleta de lixo, mas o mesmo não pode ser dito no que se refere à cobertura de esgoto. Enquanto nas áreas de baixa e média vulnerabilidade social, os porcentuais médios de domicílios ligados à rede de esgoto são de, respectivamente, 95,3\% e $93,6 \%$, no grupo de alta vulnerabilidade social este porcentual é de apenas $67,4 \%$, o que aponta para uma baixa cobertura de esgoto em muitos setores censitários deste último grupo.

As diferenças nos indicadores de escolaridade também são bastante expressivas entre os três grandes grupos de vulnerabilidade social. Enquanto a porcentagem média de responsáveis pelo domicílio com baixa escolaridade (até três anos de estudo, inclusive os sem instrução) é de apenas $5,8 \%$ no grupo de baixa vulnerabilidade social, nas áreas de média vulnerabilidade social esta porcentagem é de $16,9 \%$, atingindo expressivos $30,9 \%$ naquelas de alta vulnerabilidade.

As diferenças de escolaridade entre os três grandes grupos podem ser sintetizadas no número médio de anos de estudo do chefe de domicílio. Se no grupo de baixa vulnerabilidade social esse número chega a 11,3 anos, e no de média vulnerabilidade social é de 7,2 anos, no grupo de alta vulnerabilidade social é de apenas 5,2 anos de estudo (Tabela 2).

Se os indicadores de escolaridade são bastante contrastantes entre os três grandes grupos de vulnerabilidade social, os indicadores de renda são ainda mais contrastantes. No grupo de baixa vulnerabilidade 
TABELA2

Indicadores socioeconômicos e demográficos, por grupo de vulnerabilidade social Município de São Paulo - 2000

\begin{tabular}{|c|c|c|c|}
\hline Indicadores & $\begin{array}{c}\text { Baixa } \\
\text { vulnerabilidade } \\
\text { social }\end{array}$ & $\begin{array}{c}\text { Média } \\
\text { vulnerabilidade } \\
\text { social }\end{array}$ & $\begin{array}{c}\text { Alta } \\
\text { vulnerabilidade } \\
\text { social }\end{array}$ \\
\hline Número de domicílios & 781.735 & 1.453 .214 & 785.490 \\
\hline População residente & 2.303 .031 & 5.052 .331 & 3.046 .287 \\
\hline Distribuição dos domicílios (\%) & 25,72 & 47,82 & 25,85 \\
\hline Distribuição da população (\%) & 22,07 & 48,42 & 29,20 \\
\hline \multicolumn{4}{|l|}{ Porcentagem média (dos setores censitários) } \\
\hline Cobertura da rede de água & 99,20 & 99,57 & 95,48 \\
\hline Cobertura da rede de esgoto & 95,25 & 93,64 & 67,44 \\
\hline Coleta de lixo & 99,67 & 99,85 & 97,43 \\
\hline $\begin{array}{l}\text { Baixa escolaridade do chefe de domicílio (até } 3 \text { anos } \\
\text { de estudo, inclusive sem instrução) }\end{array}$ & 5,77 & 16,92 & 30,94 \\
\hline $\begin{array}{l}\text { Número médio de anos de estudo do chefe de } \\
\text { domicílio (em anos) }\end{array}$ & 11,27 & 7,20 & 5,15 \\
\hline Chefes de domicílio sem renda & 5,34 & 9,06 & 17,81 \\
\hline $\begin{array}{l}\text { Chefes de domicílio com renda } \\
\text { de } 0 \text { a } 3 \text { salários mínimos }\end{array}$ & 16,15 & 39,41 & 64,20 \\
\hline $\begin{array}{l}\text { Chefes de domicílio com renda } \\
\text { superior a } 5 \text { salários mínimos }\end{array}$ & 73,78 & 39,85 & 15,58 \\
\hline $\begin{array}{l}\text { Chefes de domicílio com renda } \\
\text { superior a } 20 \text { salários mínimos }\end{array}$ & 28,86 & 4,03 & 0,41 \\
\hline Renda média do chefe de domicílio (em reais) & $2.978,72$ & 937,21 & 450,08 \\
\hline Renda média do chefe de domicílio (em sal. min. 2000) & 19,73 & 6,21 & 2,98 \\
\hline População de 0 a 4 anos & 5,91 & 7,32 & 11,51 \\
\hline População de 0 a 14 anos & 17,80 & 22,55 & 31,80 \\
\hline População de 0 a 19 anos & 25,17 & 32,06 & 43,18 \\
\hline População de 65 anos ou mais & 10,11 & 7,84 & 2,64 \\
\hline Densidade domiciliar (hab./domic.) & 2,93 & 3,48 & 3,89 \\
\hline
\end{tabular}

Fonte: IBGE. Censo Demográfico de 2000; CEM-Cebrap, SAS-PMSP (2004).

social, apenas $16,2 \%$ dos chefes de domicílio possuem baixa renda (até três salários mínimos mensais, inclusive os sem renda), contra $39,4 \%$ no grupo de média vulnerabilidade social e $64,2 \%$ no de alta. ${ }^{14}$

Estas diferenças na distribuição das faixas de rendimento refletem-se na renda média do chefe por grupo de vulnerabilidade social. Enquanto a renda média mensal dos chefes de domicílio residentes em áreas de baixa vulnerabilidade social é de 2.979 reais $(19,7$ salários mínimos em
2000), naquelas de média vulnerabilidade social corresponde a 937 reais $(6,2$ salários mínimos) e nas de alta vulnerabilidade social equivale a apenas 450 reais (menos de três salários mínimos). Ou seja, a renda média de um chefe de domicílio residente em um setor censitário do grupo de baixa vulnerabilidade social é mais de seis vezes superior àquela de um chefe de domicílio do grupo de alta vulnerabilidade social.

Com relação à estrutura etária da população, a proporção de crianças de zero

\footnotetext{
${ }^{14}$ Por outro lado, a proporção de chefes ganhando acima de cinco salários mínimos (755 reais em 2000) é de 73,8\% no grupo de baixa vulnerabilidade social, $39,9 \%$ no de média e apenas $15,6 \%$ no grupo de alta vulnerabilidade social.
} 
a quatro anos de idade varia bastante entre os três grandes grupos: $5,9 \%$ no de baixa vulnerabilidade social; $7,3 \%$ no de média; e $11,5 \%$ no de alta vulnerabilidade social. ${ }^{15}$

Por outro lado, a participação de idosos (65 anos ou mais) na população apresenta padrão inverso: nos grupos de baixa e de média vulnerabilidade social, eles correspondem a, respectivamente, $10,1 \%$ e $7,8 \%$ dos habitantes; e, no de alta vulnerabilidade social, são apenas $2,6 \%$ da população.

Em síntese, cabe enfatizar que a agregação em três grandes grupos de vulnerabilidade social explicitou a existência de um expressivo contingente populacional, de mais de 3 milhões de pessoas (29\% da população do município de São Paulo), vivendo em áreas com alta vulnerabilidade social. A análise comparativa mostrou que este grupo apresenta condições socioeconômicas muito piores, além de uma estrutura etária bem mais jovem, do que os demais grupos de vulnerabilidade social.

\section{As quatro categorias de vulnerabilida- de ambiental: análise comparativa dos indicadores socioeconômicos e demográficos}

Nesta parte do trabalho, os setores censitários do grupo de alta vulnerabilidade social são classificados, de acordo com as quatro categorias de vulnerabilidade ambiental apresentadas na metodologia, as quais foram construídas com base em in- dicadores de risco e degradação ambiental, mais precisamente da combinação das variáveis relativas a proximidade de cursos d'água e cobertura de esgoto.

Portanto, neste trabalho, analisa-se a vulnerabilidade ambiental apenas no âmbito do grupo de alta vulnerabilidade social. Como dito anteriormente, o objetivo é identificar e caracterizar as situações (áreas) de sobreposição ou coexistência espacial entre vulnerabilidade social e risco/degradação ambiental, denominadas aqui de situações de vulnerabilidade socioambiental. ${ }^{16}$

A população residente em áreas (setores censitários) de alta vulnerabilidade social distribui-se da seguinte maneira entre as quatro categorias de vulnerabilidade ambiental: $60,1 \%$ (1,8 milhão de pessoas) residem em áreas com baixa vulnerabilidade ambiental (categoria 1 - alta cobertura de esgoto e fora da margem de curso d'água); 8,9\% (272 mil pessoas) vivem em áreas com média vulnerabilidade ambiental (categoria 2 - alta cobertura de esgoto e à margem de curso d'água); 20,1\% (611 mil pessoas) residem em áreas com média vulnerabilidade ambiental (categoria 3 - baixa cobertura de esgoto e fora da margem de curso d'água); e 10,9\% (331 mil pessoas) moram em áreas com alta vulnerabilidade ambiental (categoria 4 - baixa cobertura de esgoto e à margem de curso d'água) ${ }^{17}$ (Tabela 3 e Mapa 2)..$^{18}$

A seguir, comparam-se os indicadores socioeconômicos e demográficos das quatro categorias de vulnerabilidade ambiental (Tabela 3).

\footnotetext{
${ }^{15}$ Já a proporção de crianças e jovens de zero a dezenove anos de idade é de 25,2\% no grupo de baixa vulnerabilidade social, 32,1\% no de média, atingindo expressivos $43,2 \%$ no de alta vulnerabilidade social.

${ }^{16}$ Além disso, a vulnerabilidade ambiental (em relação à proximidade de cursos d'água e à cobertura de esgoto) é pouco presente nos grupos de baixa e de média vulnerabilidade social. Ou seja, outro motivo para centrar a análise apenas no grupo de alta vulnerabilidade social é o fato de a vulnerabilidade ambiental (conforme definimos) estar muito mais presente neste grupo do que naqueles de média e de baixa vulnerabilidade social. Assim, no grupo de alta vulnerabilidade social, $40 \%$ da população reside em áreas com média ou alta vulnerabilidade ambiental. Já nos grupos de média e de baixa vulnerabilidade social, essas proporções são de, respectivamente, $7,9 \%$ e $10 \%$.

${ }^{17}$ Cabe ressaltar que estes valores referem-se a 2000 , sendo que provavelmente ocorreram mudanças na distribuição porcentual da população entre os grupos de vulnerabilidade ambiental. As situações de vulnerabilidade (social e ambiental) são extremamente dinâmicas, sendo importante uma perspectiva temporal na análise das áreas ou grupos sociais mais vulneráveis, para efeito de formulação e implementação de políticas públicas. Porém, devido a limitações decorrentes da fonte de dados utilizada (censo demográfico), a análise aqui empreendida é estática, pois se refere a um único ponto no tempo (ano 2000).

${ }^{18}$ O Mapa 2 mostra apenas um "zoom" da porção nordeste da Zona Leste, para que as áreas de alta vulnerabilidade socioambiental possam ser visíveis, pois são setores com dimensões territoriais reduzidas. Se fosse apresentado um mapa com todo o município de São Paulo, estas áreas não seriam visíveis. Porém, cabe reafirmar que os dados referem-se a todo o município de São Paulo, e não apenas à Zona Leste.
} 

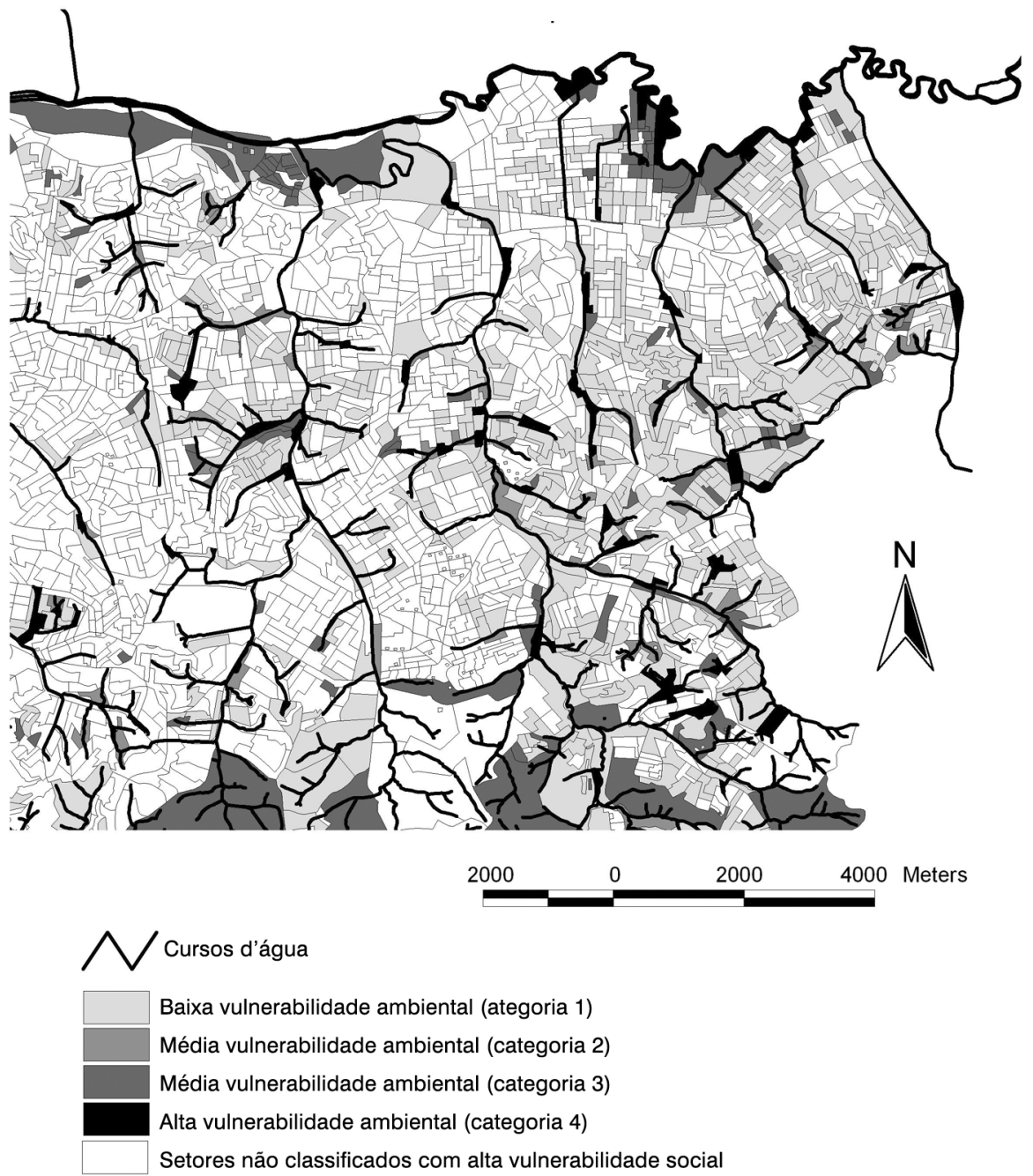

Fonte: CEM-Cebrap. Cartografia digital da rede hidrográfica de São Paulo; IBGE. Malha digital dos setores censitários do município de São Paulo; CEM-Cebrap, SAS-PMSP (2004).

Como a cobertura de esgoto do setor censitário (porcentagem de domicílios ligados à rede) foi um dos critérios para a definição das quatro categorias de vulnerabilidade ambiental, é possível observar uma polarização entre, de um lado, as faixas de média (categoria 2) e baixa vulnerabilidade ambiental e, de outro lado, as faixas de média (categoria 3) e de alta vulnerabilidade ambiental. Enquanto nas duas primeiras categorias citadas as coberturas de esgoto são de, respectivamente, $88,6 \%$ e $92,5 \%$, nas 
TABELA3

Indicadores socioeconômicos e demográficos, por categoria de vulnerabilidade ambiental Município de São Paulo-2000

\begin{tabular}{|c|c|c|c|c|}
\hline Indicadores & $\begin{array}{l}\text { Categoria } 1 \\
\text { Baixa } \\
\text { /ulnerabilidade } \\
\text { ambiental }\end{array}$ & $\begin{array}{c}\text { Categoria } 2 \\
\text { Média } \\
\text { vulnerabilidade } \\
\text { ambiental } \\
\end{array}$ & $\begin{array}{c}\text { Categoria } 3 \\
\text { Média } \\
\text { vulnerabilidade } \\
\text { ambiental } \\
\end{array}$ & $\begin{array}{c}\text { Categoria } 4 \\
\text { Alta } \\
\text { vulnerabilidade } \\
\text { ambiental }\end{array}$ \\
\hline Número de domicílios & 477.228 & 69.783 & 155.764 & 82.715 \\
\hline População residente & 1.832 .151 & 271.859 & 610.970 & 331.307 \\
\hline Distribuição dos domicílios (\%) (1) & 60,76 & 8,88 & 19,83 & 10,53 \\
\hline Distribuição da população (\%) (1) & 60,14 & 8,92 & 20,06 & 10,88 \\
\hline \multicolumn{5}{|l|}{ Porcentagem média (dos setores censitários) } \\
\hline Cobertura da rede de água & 99,28 & 98,90 & 83,06 & 94,51 \\
\hline Cobertura da rede de esgoto & 92,52 & 88,63 & 14,08 & 12,63 \\
\hline Coleta de lixo & 99,22 & 99,03 & 93,19 & 94,17 \\
\hline $\begin{array}{l}\text { Baixa escolaridade do chefe de domicílio (até } \\
3 \text { anos de estudo, inclusive sem instrução) }\end{array}$ & 28,29 & 31,67 & 34,64 & 37,69 \\
\hline $\begin{array}{l}\text { Número médio de anos estudo do chefe de } \\
\text { dmicílio (em anos) }\end{array}$ & 5,42 & 5,06 & 4,75 & 4,49 \\
\hline Chefes de domicílio sem renda & 16,61 & 16,88 & 19,97 & 21,07 \\
\hline $\begin{array}{l}\text { Chefes de domicílio com renda de } 0 \text { a } 3 \\
\text { salários mínimos }\end{array}$ & 60,69 & 65,48 & 68,81 & 73,42 \\
\hline $\begin{array}{l}\text { Chefes de domicílio com renda } \\
\text { superior a } 5 \text { saláriosmínimos }\end{array}$ & 18,13 & 14,54 & 12,12 & 9,14 \\
\hline Renda média dos chefes de domićlio (em reais) & s) 486,25 & 439,38 & 401,16 & 355,37 \\
\hline $\begin{array}{l}\text { Renda média dos chefes de domicílio } \\
\text { (em sal. min. 2000) }\end{array}$ & 3,22 & 2,91 & 2,66 & 2,35 \\
\hline População de 0 a 4 anos & 10,77 & 11,59 & 12,69 & 13,24 \\
\hline População de 0 a 14 anos & 30,83 & 32,63 & 34,59 & 35,73 \\
\hline População de 0 a 19 anos & 41,75 & 43,68 & 45,24 & 46,60 \\
\hline População de 65 anos e mais & 3,03 & 2,57 & 1,99 & 1,83 \\
\hline Densidade domiciliar (hab./domicílio) & 3,85 & 3,91 & 3,94 & 4,01 \\
\hline População residente em setores subnormais & 15,86 & 34,88 & 35,87 & 70,08 \\
\hline
\end{tabular}

Fonte: IBGE. Censo Demográfico de 2000; CEM-Cebrap, Cartografia digital da rede hidrográfica de São Paulo.

(1) Distribuição relativa apenas ao conjunto de setores censitários do grupo de alta vulnerabilidade social.

duas últimas categorias as coberturas são de $14,1 \%$ e $12,6 \%$, respectivamente.

Com relação aos indicadores de renda e escolaridade, como já visto anteriormente, os níveis são bastante baixos no grupo de alta vulnerabilidade social. Porém, neste grupo, há uma significativa variação entre as categorias de vulnerabilidade ambiental, principalmente entre os dois extremos (alta e baixa).
Assim, enquanto nas áreas classificadas na categoria de baixa vulnerabilidade ambiental (alta cobertura de esgoto e fora da margem de curso d'água), em média, $28,3 \%$ dos chefes de domicílio possuem baixa escolaridade (até três anos de estudo), naquelas de alta vulnerabilidade ambiental (baixa cobertura de esgoto e à margem de curso d'água) esta proporção chega a $37,7 \%$ (Tabela 3 ). ${ }^{19}$

\footnotetext{
19 Já nas faixas intermediárias de vulnerabilidade ambiental, o porcentual médio de chefes com baixa escolaridade é de 31,7\% (categoria 2 - alto risco e baixa degradação ambiental) e 34,6\% (categoria 3 - baixo risco e alta degradação ambiental).
} 
Nos indicadores de renda, também observa-se considerável variação entre as faixas de vulnerabilidade ambiental. A concentração de chefes de domicílio com baixa renda (até três salários mínimos, inclusive os sem renda) é significativamente mais elevada nas áreas de alta vulnerabilidade ambiental $(73,4 \%)$ do que naquelas com baixa vulnerabilidade ambiental $(60,7 \%)$.

Estas diferenças se refletem numa significativa variação da renda média do responsável pelo domicílio entre as categorias de vulnerabilidade ambiental. Enquanto nos setores censitários de baixa vulnerabilidade ambiental a renda média mensal do chefe de domicílio chega a 486 reais (3,2 salários mínimos em 2000), nos setores de alta vulnerabilidade ambiental alcança apenas 355 reais (2,3 salários mínimos) (Tabela 3).

Com relação à estrutura etária da população, as diferenças entre as faixas de vulnerabilidade ambiental também são significativas. Nas áreas de alta vulnerabilidade ambiental, a concentração de crianças de zero a quatro anos de idade chega a $13,2 \%$ da população, enquanto nas áreas de baixa vulnerabilidade ambiental é de $10,8 \% .^{20}$ Como se sabe, as crianças de zero a quatro anos são as mais vulneráveis a doenças de veiculação hídrica, o que reforça a situação de vulnerabilidade socioambiental das áreas à beira dos cursos d'água e com baixa cobertura de esgoto.

A proporção de idosos (65 anos ou mais) também varia significativamente entre as categorias de vulnerabilidade ambiental, correspondendo a $3 \%$ da população nas áreas de baixa vulnerabilidade ambiental e a apenas $1,8 \%$ naquelas de alta vulnerabilidade (Tabela 3 ).

Em resumo, os resultados mostram que as áreas (setores censitários) com alta vulnerabilidade ambiental possuem condições socioeconômicas significativamente piores, além de maior concentração de crianças e jovens, do que aquelas com baixa e mesmo com média vulnerabilidade ambiental. Algumas possíveis explicações para esta elevada concentração de problemas e riscos sociais e ambientais, nestas áreas de alta vulnerabilidade ambiental, são discutidas a seguir.

Uma primeira explicação está ligada ao fato de que as áreas de risco e degradação ambiental, muitas vezes, são as únicas acessíveis à população de mais baixa renda, por serem muito desvalorizadas no mercado de terras, devido às características de risco e falta de infra-estrutura urbana.

Outra possível explicação é que estas áreas são consideradas impróprias, pelas legislações urbanística e ambiental, para ocupação urbana, seja por oferecerem risco ambiental, seja porque são Áreas de Preservação Permanente (Código Florestal, leis $4771 / 65,7803 / 89$ e $7875 / 89$ ). Neste caso, na maioria das vezes, são áreas (públicas ou privadas) invadidas, em geral por assentamentos precários, que se configuram como áreas de favela. ${ }^{21}$

Para verificar a "hipótese" de que as áreas com alta vulnerabilidade ambiental correspondem, muitas vezes, a favelas, vamos comparar os porcentuais de população residente em setores subnormais (áreas de favela segundo definição do $\mathrm{IBGE}^{22}$ ), por categoria de vulnerabilidade ambiental. Nas áreas (conjunto de setores censitários) de baixa vulnerabilidade

\footnotetext{
${ }^{20}$ Já o porcentual de crianças e jovens de zero a 19 anos varia de $41,8 \%$ nas áreas de baixa vulnerabilidade ambiental a 46,6\% naquelas de alta vulnerabilidade ambiental.

${ }^{21}$ Assim, por um lado, as legislações urbanística e ambiental limitam o acesso a algumas áreas do ponto de vista de sua utilização privada, induzindo inadvertidamente à ocupação das áreas à beira de cursos d'água por parte dos grupos de baixa renda. Por outro lado, o mercado de terras faz com que as áreas de risco ambiental (como as à beira de cursos d'água), muitas vezes, sejam as únicas acessíveis às populações de mais baixa renda (TORRES, 1997; 2000).

${ }_{22}^{2}$ Setores especiais de aglomerado subnormal é a denominação do IBGE para áreas de favela, sendo definidos como "conjunto constituído por um mínimo de 51 domicílios, ocupando ou tendo ocupado até período recente, terreno de propriedade alheia (pública ou particular), dispostos, em geral, de forma desordenada e densa, e carentes, em sua maioria, de serviços públicos essenciais" (CEM-CEBRAP/SAS-PMSP, 2004, p. 32).
} 
ambiental, apenas $15,9 \%$ da população reside em setores subnormais. Nas áreas de média vulnerabilidade ambiental, as porcentagens de pessoas residentes em setores subnormais são ligeiramente superiores a um terço da população $(34,9 \%$ na categoria 2 e 35,9\% na categoria 3). Já nas áreas de alta vulnera-bilidade ambiental, a proporção de popula-ção residente em setores subnormais é de nada menos que 70,1\% (Tabela 3).

Assim, a maioria das áreas de alta vulnerabilidade ambiental (e social) do município de São Paulo corresponde a áreas de favela (definição do IBGE). ${ }^{23}$ Portanto, acreditamos que grande parte do esforço de planejamento e de formulação de políticas públicas para redução da vulnerabilidade socioambiental deveria estar concentrada na política habitacional, principalmente nas políticas de urbanização de favelas (TASCHNER, 2000). ${ }^{24}$

\section{Considerações finais}

Neste trabalho, procurou-se operacionalizar a categoria vulnerabilidade socioambiental, através da construção de indicadores ambientais, na escala mais desagregada possível (setores censitários), utilizando métodos e técnicas de geoprocessamento. Assim, identificando-se previamente as áreas com alta vulnerabilidade social, foi utilizada uma metodologia para construir um indicador de vulnerabilidade ambiental para estas áreas, formado pela combinação de variáveis de exposição ao risco e à degradação ambiental.

Neste sentido, a metodologia aqui utilizada está mais próxima da tradição da geografia (CUTTER, 1994; 1996), por analisar a vulnerabilidade socioambiental ao nível de áreas. Por outro lado, este trabalho também procura dialogar com os estudos dos sociólogos sobre vulnerabilidade social (MOSER, 1998; KAZTMAN et al., 1999), apesar das limitações empíricas decorrentes da utilização de áreas como unidades de análise. Além disso, este trabalho dialoga bastante com a tradição do Grupo de Trabalho de População e Meio Ambiente da ABEP, que desenvolveu e operacionalizou o conceito de populações em situação de risco, o qual representou um avanço conceitual nos estudos de risco, no contexto da demografia (TORRES, 2000; MARANDOLA e HOGAN, 2005).

Com relação aos resultados do presente trabalho, verificou-se que, no interior do grupo de alta vulnerabilidade social, existem diferenças significativas nas condições socioeconômicas e demográficas, relacionadas às diversas categorias de vulnerabilidade ambiental. Assim, em algumas áreas, a vulnerabilidade social é agravada por situações de risco e degradação ambiental. Além disso, as áreas com alta vulnerabilidade ambiental apresentam condições socioeconômicas significativamente piores, além de maior concentração de crianças e jovens, do que aquelas com menor grau de vulnerabilidade ambiental, o que revela a existência de áreas críticas, onde ocorre uma forte concentração de problemas e riscos sociais e ambientais. Criam-se assim situações em que justamente os grupos sociais com maiores níveis de pobreza e privação social (e portanto com menor capacidade de reação às situações de risco) vão residir nas áreas com maior exposição ao risco e à degradação ambiental, configurando-se situações de alta vulnerabilidade socioambiental.

Esta sobreposição ou cumulatividade de riscos e problemas sociais e ambientais representa um grande desafio para as políticas públicas, que, na maioria das vezes, são compartimentalizadas segundo áreas de intervenção setorial. Neste sentido, este trabalho pode trazer subsídios relevantes para o planejamento de políticas públicas,

\footnotetext{
${ }^{23}$ Assim, apesar de a população residente em áreas de alta vulnerabilidade ambiental representar apenas $11 \%$ da população do grupo de alta vulnerabilidade social, ela corresponde a quase $30 \%$ da população favelada deste grupo.

${ }^{24}$ Porém, cabe destacar que a mera remoção desta população favelada não resolve o problema, pois, em geral, apenas desloca esta população para áreas periféricas distantes e muitas vezes sem serviços e infra-estrutura urbana, gerando assim novas situações de vulnerabilidade socioambiental.
} 
ao identificar e caracterizar as áreas críticas, com alta vulnerabilidade social e ambiental, as quais poderiam ser alvo de políticas focalizadas, obtendo-se resultados bastante significativos na redução da vulnerabilidade, tendo em vista que o número de famílias residentes nas áreas de maior vulnerabilidade socioambiental não é tão grande.

Como mencionado anteriormente, a política habitacional e, principalmente, as políticas de urbanização de favelas poderiam ter grande eficácia na redução das

\section{Referências bibliográficas}

COMISIÓN ECONÓMICA PARA AMÉRICA LATINA Y EL CARIBE - CEPAL. Sociodemographic vulnerability: old and new risks for communities, households and individuals. Summary and conclusions. Brasilia: UNA, 2002.

CEM-CEBRAP, SAS-PMSP. Mapa da vulnerabilidade social da população da cidade de São Paulo. São Paulo: Sesc-SP, 2004.

CUTTER S.L. Vulnerability to environmental hazards. Progress in Human Geography, v.20, n. 4, p.529-539, dec. 1996.

. (Org.) Environmental risks and hazards. London: Prentice-Hall, 1994.

HOGAN, D.J.; MARANDOLA JR., E. Towards an interdisciplinary conceptualization of vulnerability. Population, Space and Place, n. 11, p. 455-471, 2005.

IHDP. Newsletter of the International Human Dimensions Programme on Global Environmental Change, Bonn, n. 2, 2001.

JACOBI, P. R. Moradores e meio ambiente na cidade de São Paulo. Cadernos CEDEC, São Paulo, n. 43, 1995.

KASPERSON, J.; KASPERSON, R. International workshop on vulnerability and global environmental change. Stockholm: SEI, 2001.

KAZTMAN, R.; BECCARIA, L.; FILGUEIRA, F.; GOLBERT, L.; KESSLER, G. Vulnerabilidad, activos y exclusión social situações de alta vulnerabilidade socioambiental, no município de São Paulo, uma vez que a maioria das áreas nesta situação é de favelas. Além disso, seria muito importante que as diversas políticas públicas que lidam com as situações de vulnerabilidade socioambiental (políticas de habitação, saneamento e meio ambiente) fossem formuladas (e implementadas) conjuntamente e de maneira integrada, levando em conta a distribuição desigual destas situações no espaço urbano.

en Argentina y Uruguay. Santiago de Chile: OIT, 1999.

MARANDOLA JR., E.; HOGAN, D.J. Vulnerabilidade e riscos: entre geografia e demografia. Revista Brasileira de Estudos de População, São Paulo, v.22, n.1, p.2953, 2005.

MOSER, C. The asset vulnerability framework: reassessing urban poverty reduction strategies. World Development, New York, v.26, n.1, 1998.

TASCHNER, S. P. Degradação ambiental em favelas de São Paulo. In: TORRES, H.; COSTA, H. (Orgs.). População e meio ambiente: debates e desafios. São Paulo: Editora Senac, 2000, p.271-297.

TORRES, H. A demografia do risco ambiental. In: TORRES, H.; COSTA, H. (Orgs.). População e meio ambiente: debates e desafios. São Paulo: Editora Senac, 2000, p.53-73.

Desigualdade ambiental em São

Paulo. Tese de doutorado em Ciências Sociais. Campinas: IFCH-Unicamp, 1997.

TORRES, H.; MARQUES, E. Tamanho populacional das favelas paulistanas. Ou os grandes números e a falência do debate sobre a Metrópole. ENCONTRO NACIONAL DE ESTUDOS POPULACIONAIS, 13, Ouro Preto, 2002. Anais... Belo Horizonte: ABEP, 2002.

Reflexões sobre a hiperperiferia: novas e velhas faces da pobreza no entorno 
metropolitano. Revista Brasileira de Estudos Urbanos e Regionais, n. 4, p. 4970, 2001.

TORRES, H.; MARQUES, E.; FERREIRA, M.P.; BITAR, S. Pobreza e espaço: padrões de segregação em São Paulo. Revista do Instituto de Estudos Avançados, IEA-USP, v.17, n. 47, p. 97-128, jan./abr., 2003.

\section{Abstract}

Socio-environmental vulnerability in the Metropolis of São Paulo, Brazil: a socio-demographic analysis of spatial coexistence of social and environmental risks and problems

The objective of this article is to identify and analyze population groups living in situations of socio-environmental vulnerability in São Paulo, by constructing environmental indicators on a disaggregated scale. We define socio-environmental vulnerability as the spatial coexistence of high social vulnerability together with areas of environmental risk and deterioration. The methodology is based on a Geographical Information System (GIS) that provides information on the network of waterways and the layers of the census tracts in the municipality of São Paulo. We first identify the census tracts that show high social vulnerability, using a Social Vulnerability Map (CEM-CEBRAP / SAS-PMSP, 2004). Next we select the census tracts that are near watercourses, have low sewage treatment, and are near areas with high environmental vulnerability. The results show significant differences in socioeconomic and demographic conditions among the various categories of environmental vulnerability.

Key words: Socio-environmental vulnerability. Environmental risk. Socio-environmental indicators. Social vulnerability. Metropolis of São Paulo. Population groups at risk. Geographic information systems. 